\title{
BRAIN MACROPHAGES IN HUMAN CORTICAL CONTUSIONS AS INDICATOR OF SURVIVAL PERIOD
}

\author{
MANFRED OEHMICHEN ${ }^{a}$, WOLFGANG EISENMENGER ${ }^{b}$, GERHARD RAFF ${ }^{c}$, \\ GERHARD BERGHAUS ${ }^{\mathrm{a}}$ \\ ${ }^{\mathrm{a}}$ Institute for Forensic Medicine, University of Cologne, ${ }^{\mathrm{b}}$ Institute for Forensic Medicine, \\ University of Munich and ${ }^{c}$ Institute for Forensic Medicine, University of Tübingen, \\ Tübingen (F.R.G.)
}

(Received April 25, 1985)

(Revision received August 30, 1985)

(Accepted October 23, 1985)

\section{Summary}

The aim of this study was to establish a morphologic time scheme with which cases of cerebral contusion with unknown survival periods can be dated. Our study of 275 cases was limited to qualitative and quantitative changes in macrophages. The appearance of macrophages and their distribution as well as their content of neutral fat, esterified cholesterol, erythrocytes, siderin, hematoidin, and ceroid were correlated with the survival period. For each cytologic criterium, the observation period, distribution-free limits of tolerance, and relative frequency of identification in different survival periods were determined, and the limits of confidence calculated. The findings permit the dating of trauma in cases with unknown survival periods. Moreover, the probability of this dating was calculated.

Key words: Cortical contusion; Survival period; Dating; Macrophages; Brain; Trauma

\section{Introduction}

The cerebral contusion is a regularly identifiable morphologic phenomenon of cortical hemorrhage in blunt head injury. Extravasated blood and necrotic neurogenic tissue are broken down in accordance with pathophysiologic mechanisms, some of which have been clarified, and some of which are still under discussion [cf. 23,24]. In this degenerative process, extravasated erythrocytes, blood serum, and tissue necrosis apparently act as a chemotactic stimulus which, in turn, results within a few minutes in leukocyte emigration. Since this phenomenon, together with many other changes of a predominantly cytologic nature, occurs during certain time intervals, a scheme can be set up to date the survival periods within certain limits

Address all correspondence to: Prof, Dr, med. M. Oehmichen, Institut für Rechtsmedizin der Universität zu Köln, Melatengürtel 60/62, 5000 Köln 30, F.R.G. 
$[4,8,18,21,25]$. Related studies on ischemic brain injury have also shown certain similarities in the temporal course $[14,16,30,32]$.

Extravasated monocytes or macrophages are first observable in cortical contusions as early as $12-14 \mathrm{~h}$ after the traumatic event. The distribution of macrophages in and around the hemorrhage site varies depending on the length of the survival period. The function of the macrophages is the removal of necrotic cells, cell debris, and freed material by ingestion and digestion. The removal rate varies depending, among other things, on the size of the material recognized as "foreign."

Both the different localization and functional state of macrophages in cortical contusions depend on the survival period. These characteristics, therefore, can be used to date cases of traumatic cortical hemorrhage with unknown survival periods.

\section{Materials and methods}

\subsection{Material}

This study is based on 275 cases of cortical hemorrhage with variously long survival periods $(0-58$ years $)$. Any case that did not meet the following requirements was excluded from the study:

1. Known survival period,

2. Restriction of hemorrhage primarily to cortex,

3. Patient at least 15 years old at time of head injury,

4. No clinical or morphologic signs of intravital brain death.

The quality or quantity of other trauma-induced effects and the cause of death were not considered.

\subsection{Histologic procedures}

After fixation in formalin, the autopsy material was either embedded in paraffin and cut into $5 \mu \mathrm{m}$ thick sections, or frozen sections were prepared.

Neutral fat was identified in frozen sections by scarlet red and in paraffinembedded sections by hematoxylin and eosin ( $\mathrm{H}$ and $\mathrm{E})$, Luxol fast blue, Prussian blue, van Gieson, cresyl violet, and according to Klüver-Barrera.

The microscopic investigation was performed by polarization or by transmitted light fluorescence with UV light using a Zeiss Photomicroscope III (Oberkochem/FRG).

\subsection{Histologic evaluation}

Macrophages were basically identified by light microscopic criteria: mononuclear elements with predominantly indented or rounded nucleus containing loosely structured chromatin, and swollen cell body that was clearly differentiatable from the surrounding neurogenic tissue. Findings obtainable on HE-stained sections were not essentially changed by the demonstration of lysozyme as macrophage marker. 
A semiquantitative differentiation was carried out to determine the topographical distribution of macrophages. The following characteristics were differentiated in each case:

1. Predominantly perivascular macrophages within the neuropil;

2. Disseminated, single macrophages;

3. Many macrophages diffusely interspersed throughout tissue;

4. Beginning demarcation by macrophages; and

5. Pronounced demarcation by macrophages.

Qualitative differentiation of single macrophages was based on identifiable ingested material. The following types of macrophages were differentiated:

1. Macrophages, regardless of ingested material;

2. Macrophages with intracellular neutral fat;

3. Macrophages with intracellular anisotropic lipids;

4. Macrophages with ingested erythrocytes (erythrophages);

5. Macrophages with intracellular siderin (siderophages);

6. Macrophages with intracellular ceroid (ceroid-phages); and

7. Macrophages with intracellular hematoidin (hematoidin-phages).

\subsection{Quantitative evaluation}

The duration of each post-traumatic interval was recorded in minutes, hours, days, or years as well as by a logarithm of minutes. In those cases with identifiable macrophages, including erythrophages, siderophages, and hematoidin-phages, a distinction was made between cases with a few macrophages (10 macrophages/microscopic field; lens magnification, $\times 25$; eyepiece magnification, $\times 10$ ) and cases with many macrophages. The cases were further classified according to the same or a similar survival period. This classification was based on identical time intervals related to a logarithmic presentation of time ([logarithm] log min).

The following information was obtained by additional evaluation of all material:

1. First and last time at which a definite histomorphologic criterium was demonstrable in the post-traumatic interval (observation period);

2. Frequency of criterium in relation to total number of cases examined within this observation period (relative frequency);

3. Limits of confidence for observed relative frequency (estimated according to Clopper and Pearson [6]) with a statistical reliability of 95\%;

4. Distribution-free (independent) tolerance limit [28] in which certain criteria appeared within the respective observation period with a statistical reliability of $95 \%$. 


\section{TABLE 1}

\section{SUMMARY OF RESULTS}

Observation periods for the considered cytomorphologic criteria in cortical contusions (columns 1 and 2). Relative frequency of cases examined in which respective cytomorphologic criteria were observed in cortical contusion (column 5 ). The limits of confidence for the respective relative frequency of those cases demonstrating the individual cytomorphologic criteria - estimated with a statis tical reliability of $95 \%$ according to Clopper and Pearson (column 6). Calculation of distribution-free tolerance limits with which respective cytomorphologic criteria may be expected with $95 \%$ reliability of the survival periods within observation period after traumatic event (column 7).

\begin{tabular}{|c|c|c|c|c|c|c|c|}
\hline \multirow[t]{4}{*}{$\begin{array}{l}\text { Cytomorphologic } \\
\text { alterations }\end{array}$} & \multicolumn{2}{|c|}{$\begin{array}{l}\text { Demonstration time } \\
\text { correlated with } \\
\text { survival time of } \\
\text { traumatic event } \\
\text { (observation } \\
\text { period) }\end{array}$} & \multirow[t]{2}{*}{$\begin{array}{l}\text { Total number } \\
\text { of examined } \\
\text { cases during } \\
\text { observation } \\
\text { period }(n)\end{array}$} & \multirow[t]{2}{*}{$\begin{array}{l}\text { Number of } \\
\text { cases with } \\
\text { cytomorpho- } \\
\text { logic alterations } \\
\text { (observations) }\end{array}$} & \multirow[t]{2}{*}{$\begin{array}{l}\text { Relative frequency } \\
\text { of observations } \\
\text { (data expressed } \\
\text { in percent) }\end{array}$} & \multirow[t]{2}{*}{$\begin{array}{l}\text { Estimated limits } \\
\text { of confidence } \\
\text { [6] (data } \\
\text { expressed in } \\
\text { percent) }\end{array}$} & \multirow[t]{2}{*}{$\begin{array}{l}\text { Distribution-free } \\
\text { tolerance limit } \\
\text { with } 95 \% \text { relia- } \\
\text { bility (data } \\
\text { expressed in } \\
\text { percent) }\end{array}$} \\
\hline & $\begin{array}{l}\text { First } \\
\text { appeara }\end{array}$ & $\begin{array}{l}\text { Last } \\
\text { appearance }\end{array}$ & & & & & \\
\hline & \multicolumn{7}{|c|}{ Column } \\
\hline & 1 & 2 & 3 & 4 & 5 & 6 & 7 \\
\hline Macrophages & 11.5 & 58 a & 210 & 194 & 92.4 & $90.8-97.6$ & 97 \\
\hline $\begin{array}{l}\text { Macrophage } \\
\text { distribution } \\
\text { perivascular }\end{array}$ & 11.5 & $6.5 \mathrm{~d}$ & 12 & 6 & 50.0 & $21.0-78.9$ & 41 \\
\hline
\end{tabular}




\begin{tabular}{|c|c|c|c|c|c|c|c|}
\hline single & $11.5 \mathrm{~h}$ & $58 \mathrm{a}$ & 59 & 27 & 45.8 & $32.7-59.2$ & 83 \\
\hline $\begin{array}{l}\text { diffuse (many) } \\
\text { beginning }\end{array}$ & $24.0 \mathrm{~h}$ & $240 \mathrm{~d}$ & 78 & 57 & 73.1 & $61.8-82.5$ & 92 \\
\hline demarcation & $14 \mathrm{~d}$ & $1 \mathbf{a}$ & 11 & 10 & 90.9 & $58.7-99.7$ & 60 \\
\hline demarcation & $6 \mathrm{~d}$ & $15 \mathrm{a}$ & 29 & 19 & 65.5 & $45.6-82.0$ & 77 \\
\hline Lipophages & $24 \mathrm{~h}$ & $30 \mathrm{a}$ & 131 & 100 & 76.3 & $67.8-83.1$ & 95 \\
\hline \multicolumn{8}{|l|}{ Anisotropic } \\
\hline lipids & $10 \mathrm{~d}$ & $28 \mathrm{a}$ & 99 & 34 & 34.3 & $25.0-44.5$ & 86 \\
\hline Erythrophages & $16 \mathrm{~h}$ & $150 \mathrm{~d}$ & 160 & 126 & 78.8 & $72.2-85.1$ & 96 \\
\hline Siderophages & $71 \mathrm{~h}$ & $44 \mathrm{a}$ & 154 & 141 & 91.6 & $81.3-91.9$ & 96 \\
\hline Hematoidin & $12 \mathrm{~d}$ & $365 \mathrm{~d}$ & 67 & 33 & 49.3 & $36.8-61.7$ & 86 \\
\hline Ceroid & $101 \mathrm{~h}$ & $210 \mathrm{~d}$ & 46 & 29 & 63.0 & $47.5-76.8$ & 84 \\
\hline
\end{tabular}




\section{Results}

First, the observation period for each criterium, i.e. the post-traumatic interval within which this criterium was identifiable, was determined. The individual observation periods in Table 1 (columns 1 and 2; for graphic presentation, see Fig. 1) already show the basic scheme which, after consideration of the cytomorphologic criteria mentioned above, gives indications for the dating of brain injury in a case with an unknown survival period.

This then brings up the question of whether all possible cases are included in the observation periods, i.e. what percentage of cases will fall outside these periods. To answer this question, the distribution-free limits of tolerance were calculated for the single criteria (see Table 1, column 7). Approximately $90 \%$ of all cases are included in the observation periods of most criteria, in other words, about $10 \%$ of the cases fall outside the periods (i.e. either earlier or later).

Initially, it was impossible to cite the probability with which a criterium was to be expected at any particular point in time within the observation period. To determine the percentage of cases with any one criterium after certain post-traumatic intervals (for relative frequency, cf. Figs. 2-6), the

- Macrophages

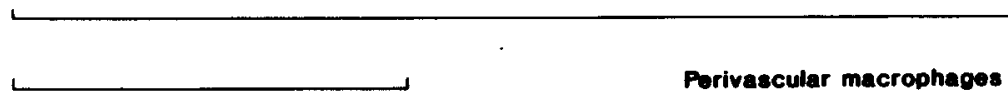

Dise. single m.

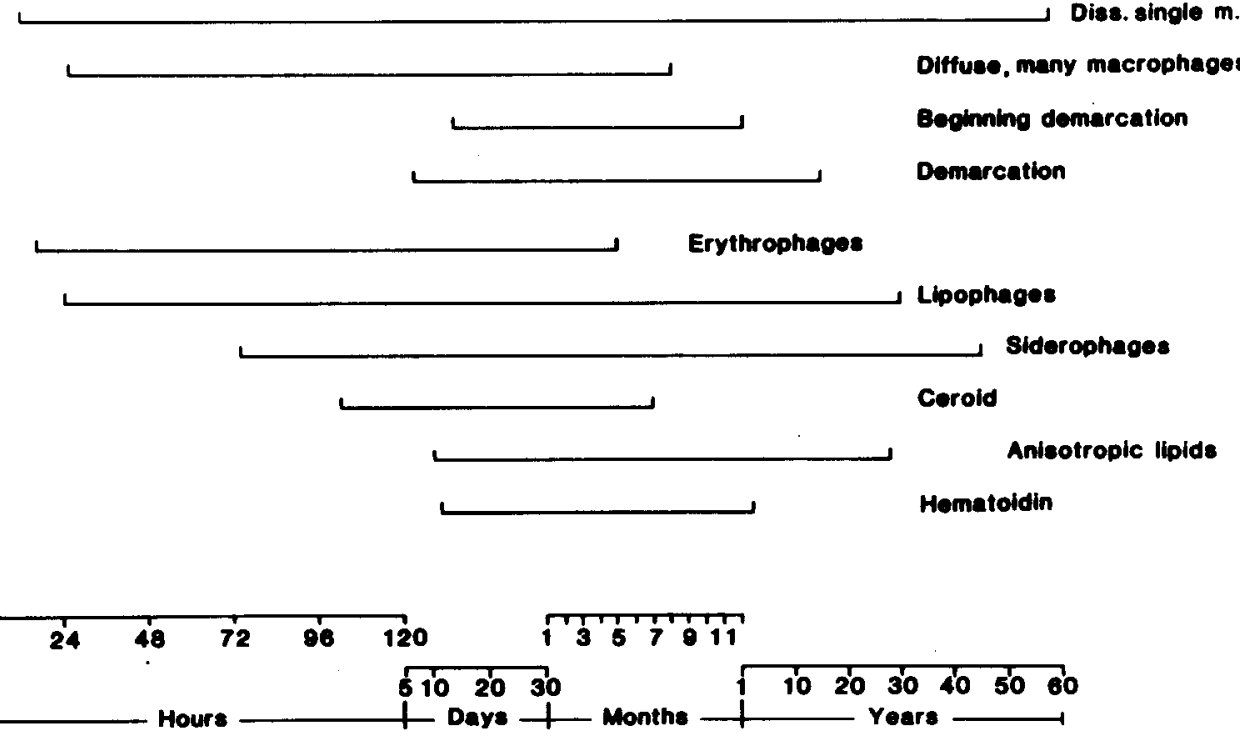

Fig. 1. Observation periods for individual histomorphologic criteria during different survival periods. 

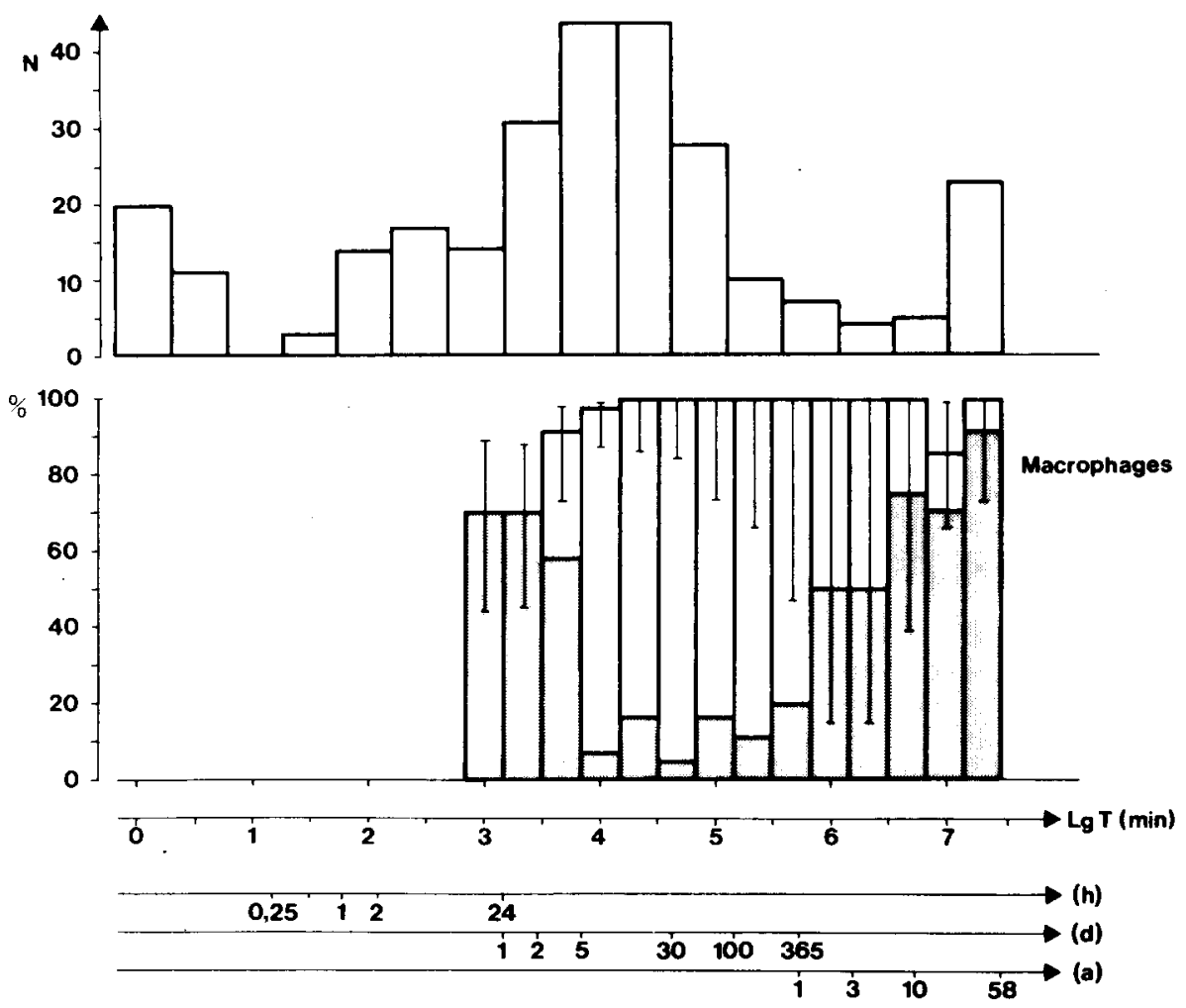

Fig. 2. Identification of macrophages during different survival periods (logarithmic presentation of time). Upper figure shows total number of examined cases $(n=275)$ that were classified in groups with identical survival periods. Lower figure shows percentage of cases with macrophages after a certain survival period (total column). The percentage of cases with only a "few" macrophages is entered separately (shaded portion of column). Lines at top of columns designate limits of confidence with $95 \%$ reliability.

typical observation periods for each histomorphologic criterium were recorded and the examined cases in this period assigned according to different survival periods. The reliability with which any one criterium can be expected during any given post-traumatic interval was established by determining the limits of confidence.

The following associations were also demonstrated for each criterium:

\subsection{Identification of macrophages (Fig. 2)}

Macrophages were definitely observed for the first time $11.5 \mathrm{~h}$ after the traumatic event; they were identifiable in the traumatically injured region of the brain during virtually every examined survival period time up to 58 years. The percentage of cases in which comparatively few macrophages could be observed was determined: their percentage proved comparatively high, 


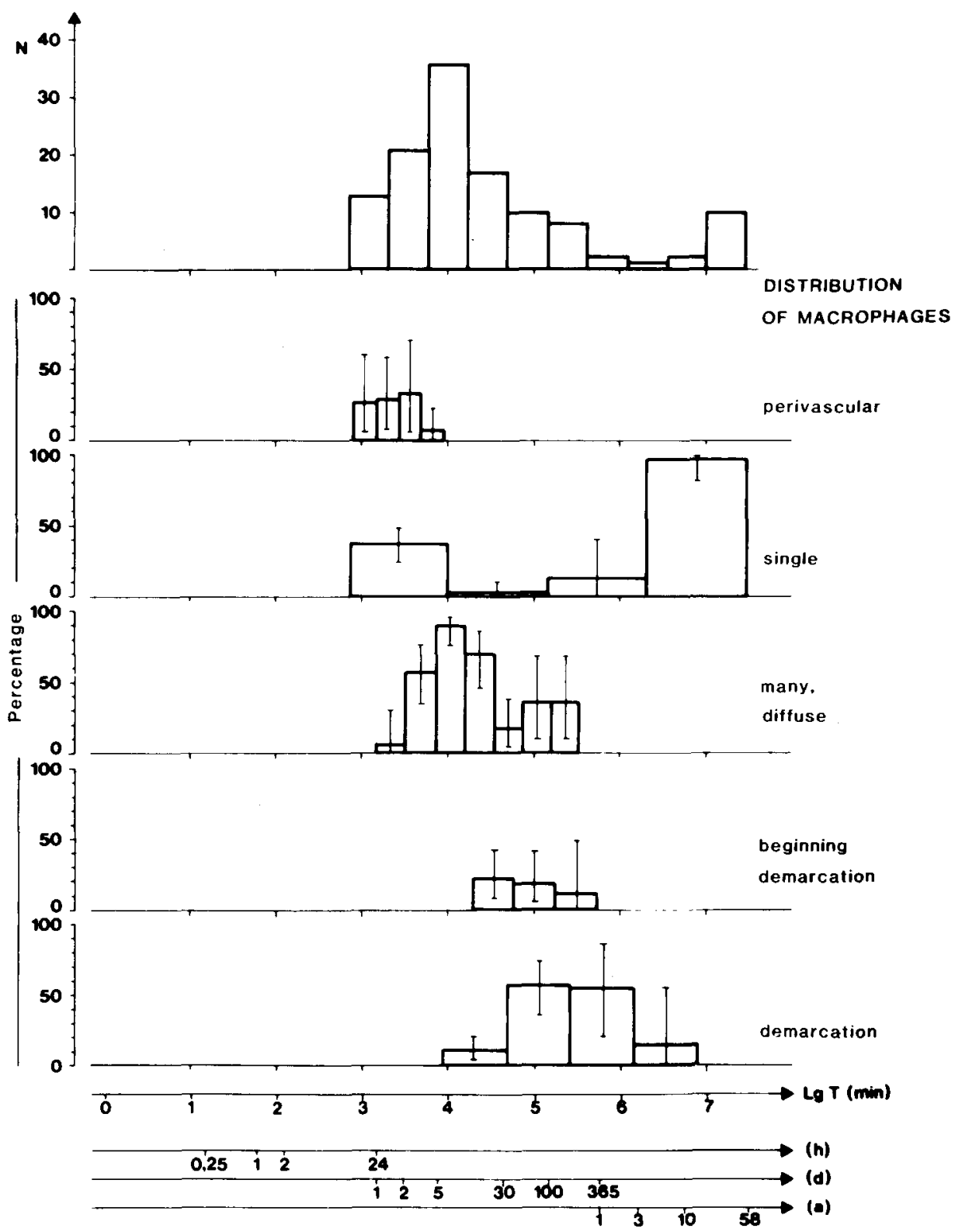

Fig. 3. Distribution of macrophages during different survival periods (logarithmic presentation of time). Uppermost figure shows total number of examined cases $(n=131)$ in which distribution was assessed. Like in Fig. 2, cases were assigned to groups with the same survival period. The other 5 figures show distribution and number of macrophages in cases with different survival periods. Intervals of confidence for each survival class are cited. 


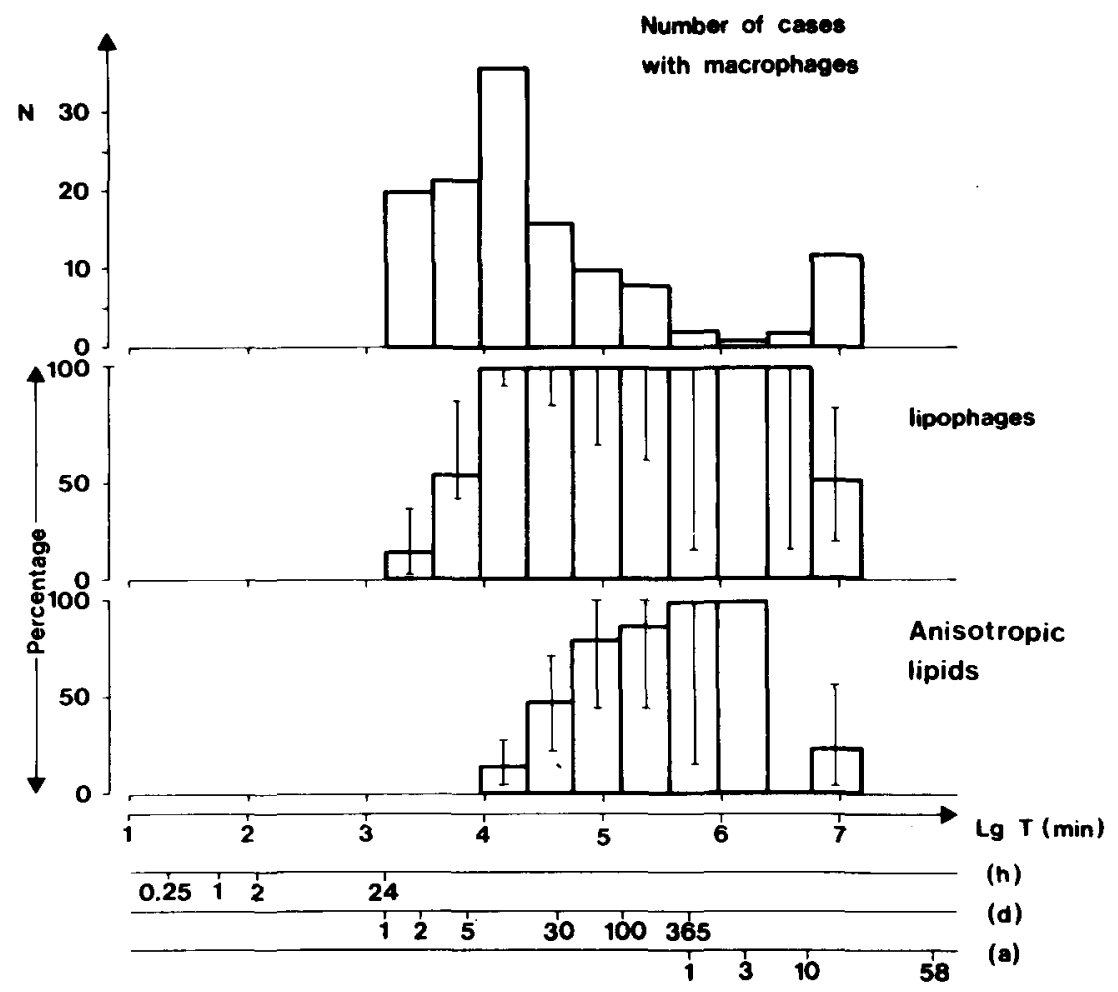

Fig. 4. Identification of neutral fat and anisotropic lipids in phagocytes (crystals in lipophages) during different survival times (logarithmic presentation of time). Upper figure shows the number of examined cases during observation period for lipophages $(n=131)$; the second figure, the percentage of cases with cells containing lipids; and the third figure, the percentage of cases with crystalline-positive lipids in macrophages. Both the second and third figures give the limits of confidence for each time class.

particularly during the short interval (up to 5 days) and the long intervals (1 year or more).

\subsection{Distribution of macrophages (Fig. 3)}

As mentioned previously, five different distribution types were distinguished. The first macrophages occurred either singly (Fig. 7a) or perivascularly (Fig. 7b). Whereas perivascular macrophages were found only within the first few days after the injury, single macrophages appeared during the first 5 days and then peaked again 10 or more years later. Moreover, this differentiation confirmed that the initial distribution is relatively diffuse (Fig. 8a), and that macrophages later accumulate locally at the boundary between intact and necrotic brain tissue (Fig. 8b), leading, in part, to clear demarcation (Fig. 9). 

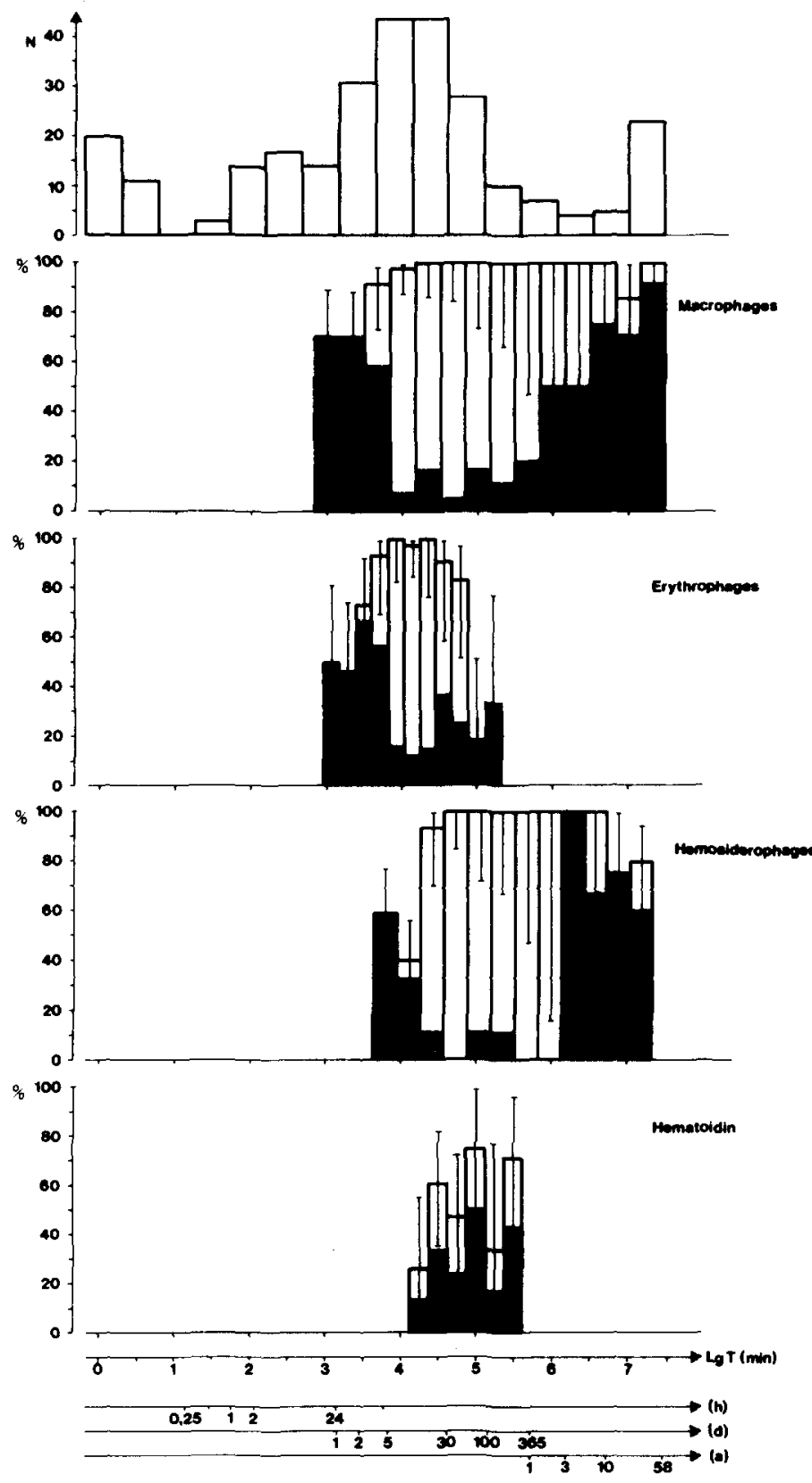

Fig. 5. Identification of macrophages, erythrophages, siderophages, and hematoidin in cases with different survival periods after cortical hemorrhage. The two uppermost figures show the total number of cases $(n=275)$ and the percentage of cases with macrophages; and Figs. 3 through 5 , the percentage of cases for each demonstrated single criterium in dependency on the post-traumatic survival period. The percentage of cases with only slightly pronounced single criterium (shaded portion of column) and the limits of confidence for each time class are presented. 

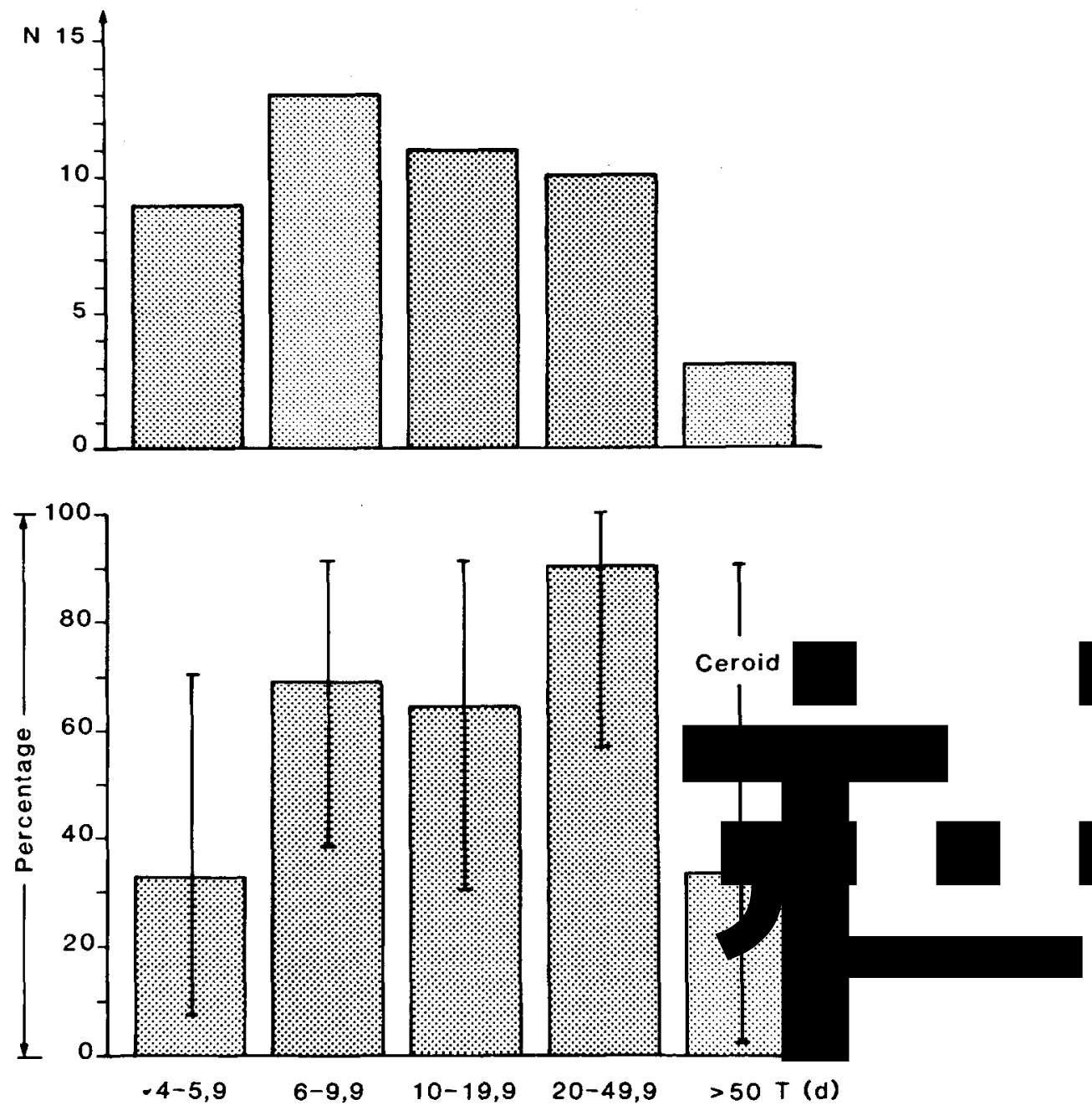

Fig. 6. Ceroid identification in macrophages at different time periods after traumatic event. Intervals of confidence are presented.

\subsection{Intracellular lipid (Fig. 4)}

Lipid accumulation in the cytoplasm of macrophages (demonstrated by scarlet red staining - cf. Figs. 7-9) exceeding that considered normal for monocytes was briefly observed after the first appearance of these cells, i.e. as early as $24 \mathrm{~h}$ after the traumatic event. Positive identification in the traumatically altered cortex was possible up to 30 years after the injury. The percentage of cases with lipophages was low in the first few days after the event but then increased until, 5 or 6 days after the injury, lipid storage was identified in macrophages of all cases. 

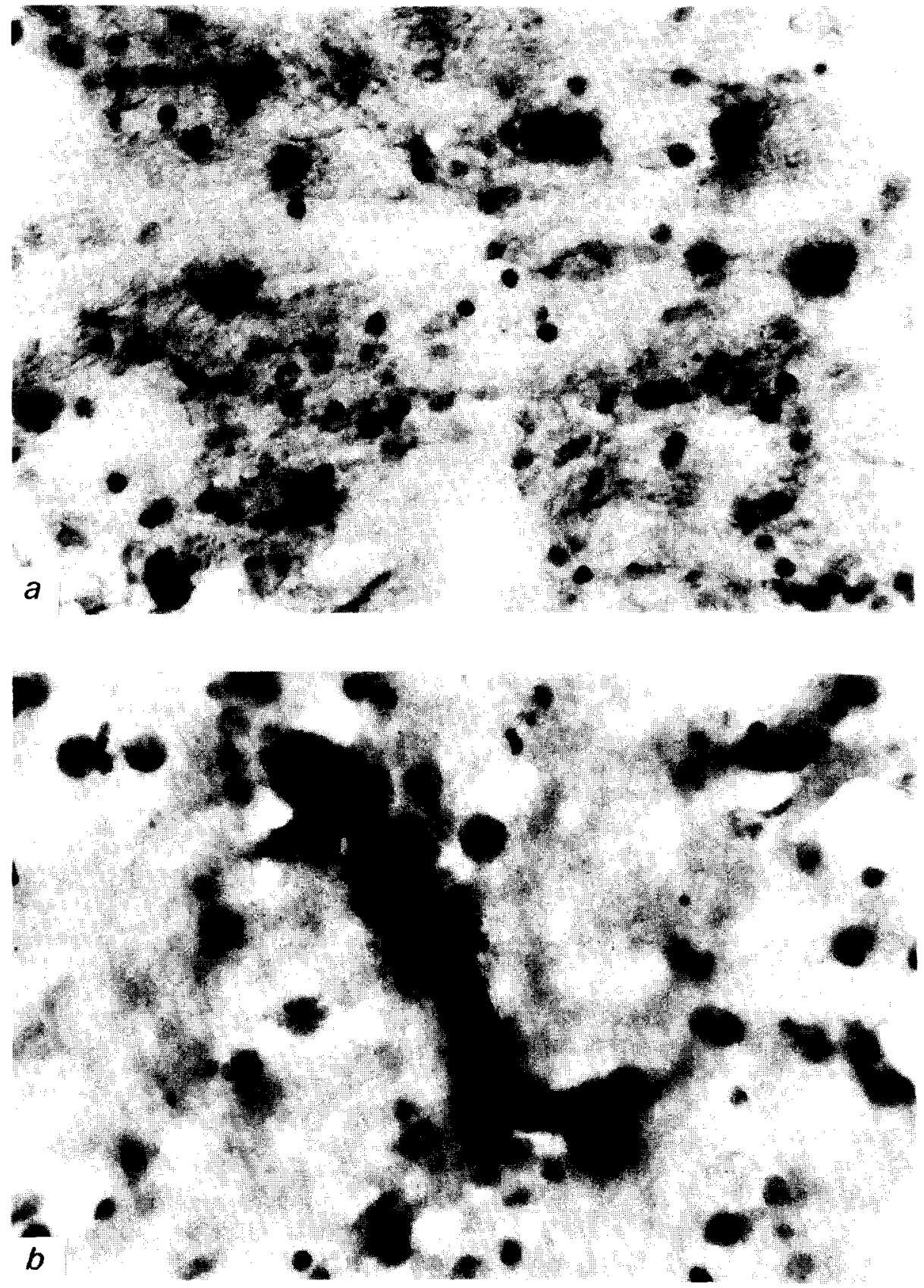

Fig. 7. Single (a) and perivascular (b) lipid-containing macrophages 2 days after traumatic event. (scarlet red/hemalum; $a: \times 500, b: \times 1200$ ) 


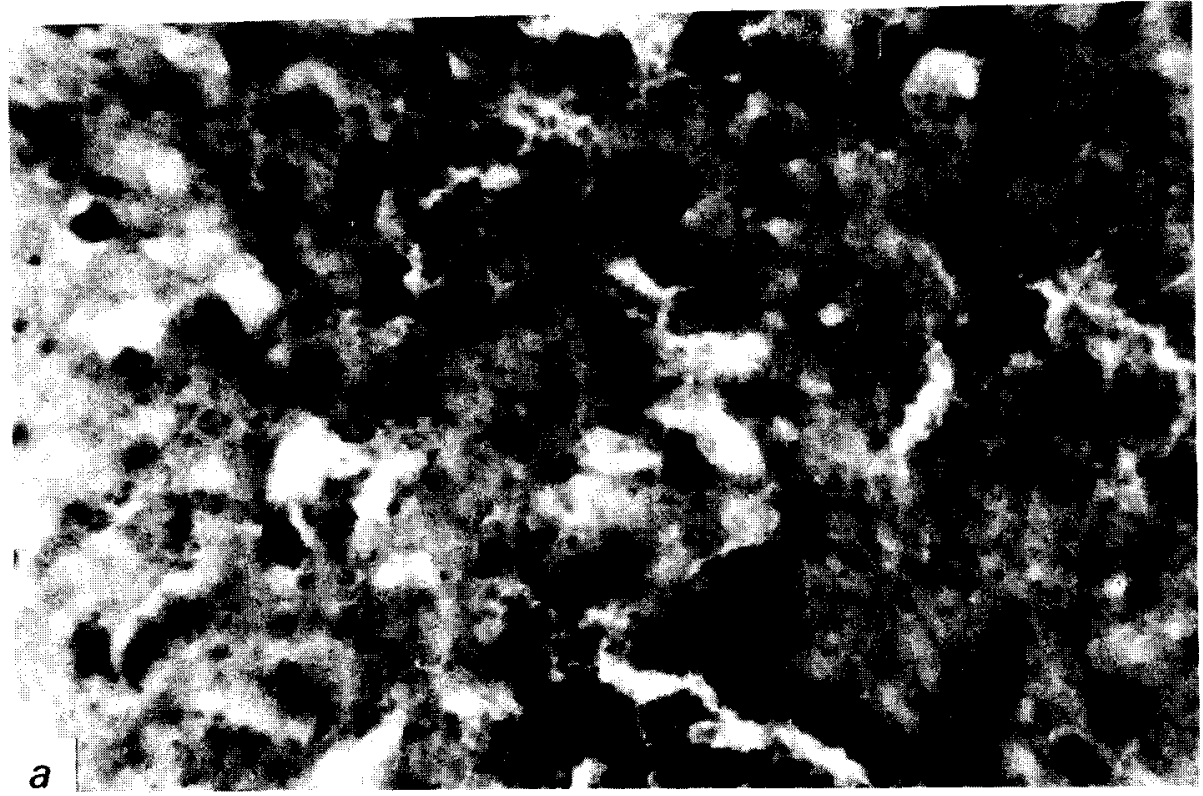

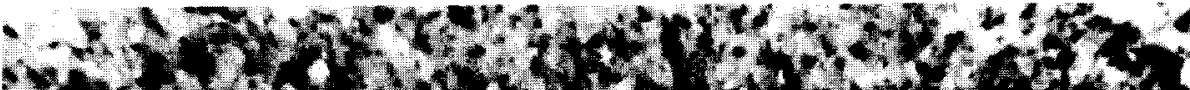

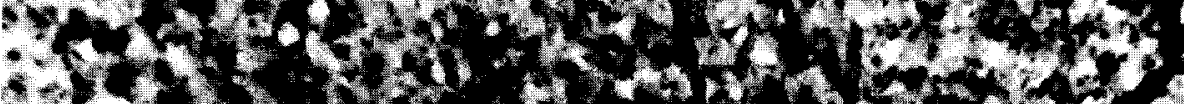

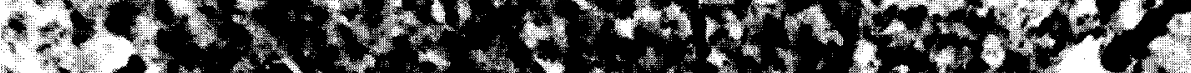

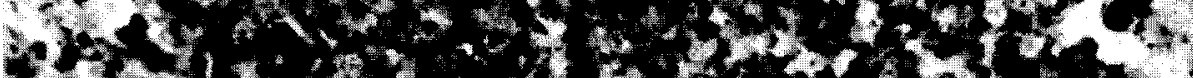

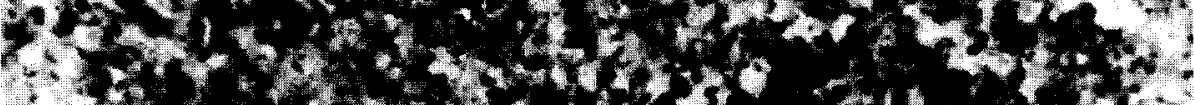

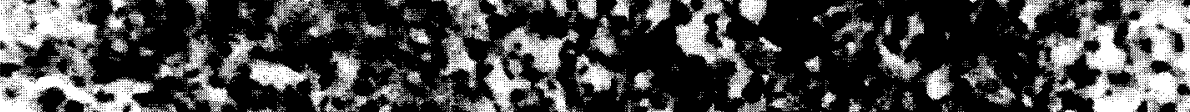

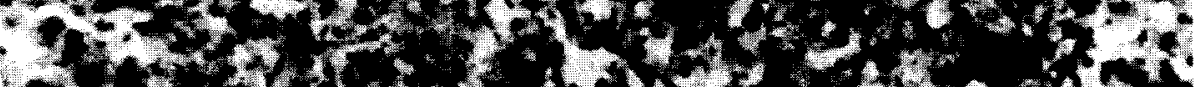

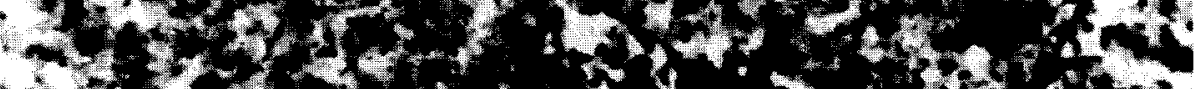

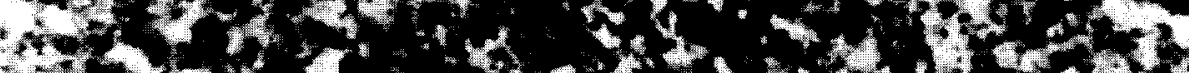

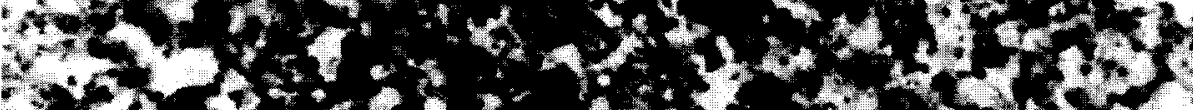

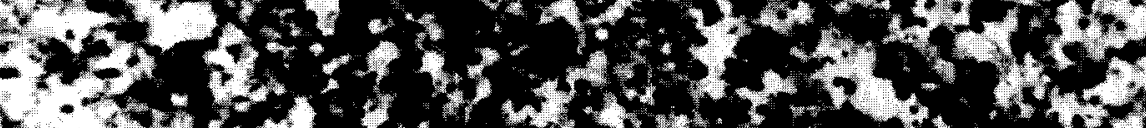

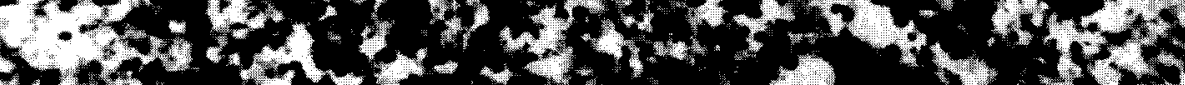

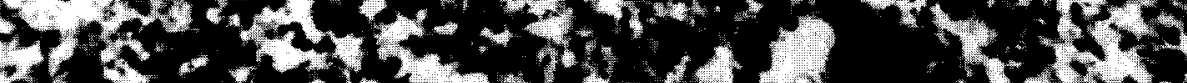
- H,

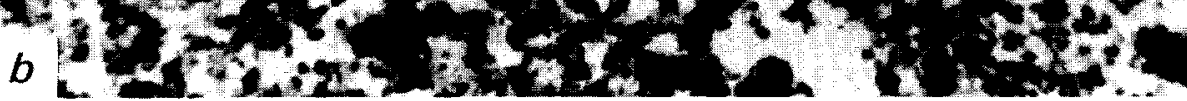

Fig. 8. Many disseminated macrophages without clearly defined necrotic field. (scarlet $\mathrm{red} /$ hemalum; $\mathrm{a}: \times 200, \mathrm{~b}: \times 1200$ ) 

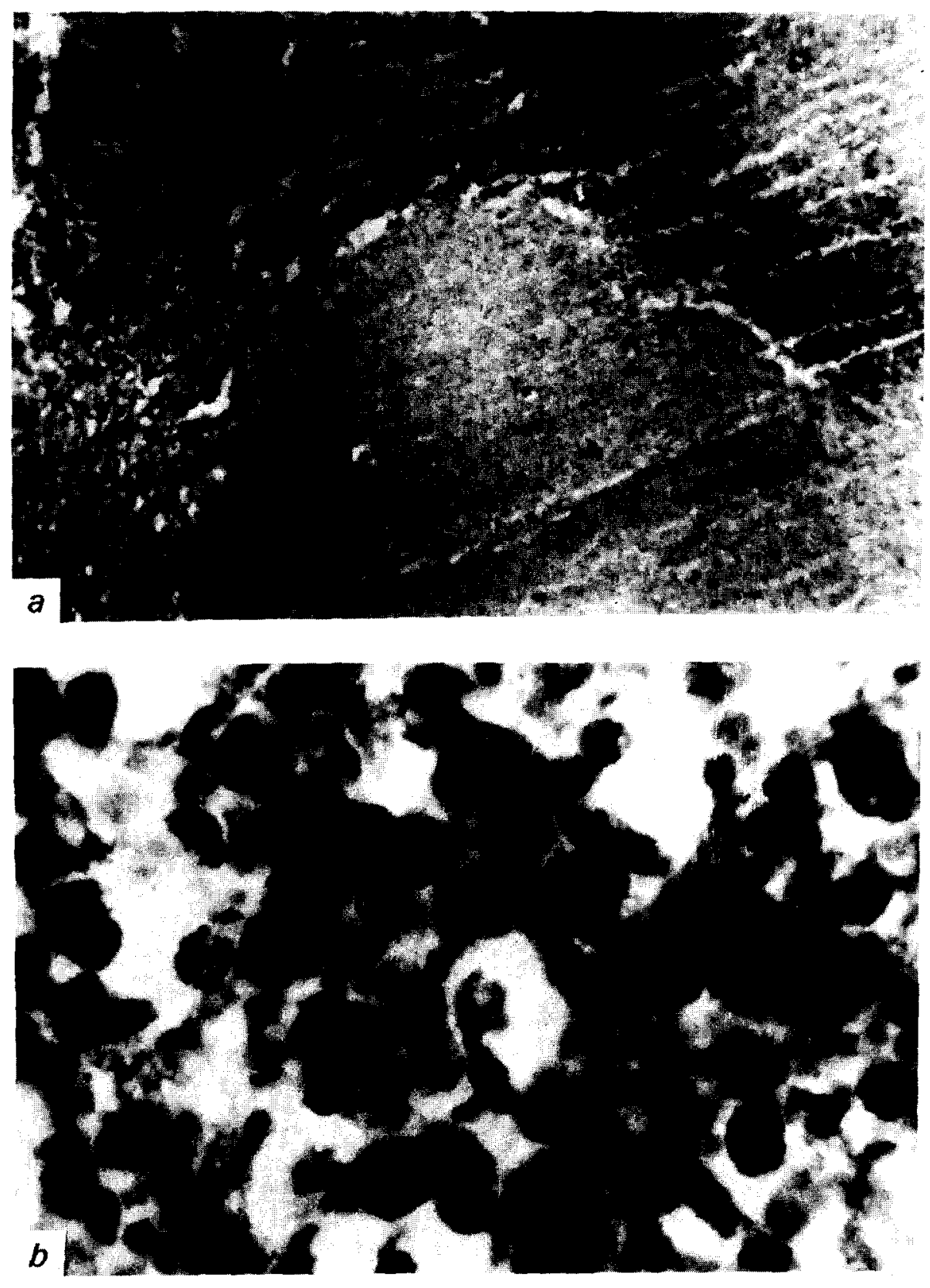

Fig. 9. Demarcating distribution of macrophages within clearly defined necrotic field of brain. (scarlet red/hemalum; a: $\times 150, b: \times 1200$ ) 
Anisotropic lipids were identified on scarlet red-stained frozen sections by polarization microscopy (Fig. 10). These lipids were first observed 10 days after the injury and were still evident for 28 years in single cases. Anisotropy of stored lipids was observed in all investigated cases (100\%) only in survival periods exceeding 5 months. This finding, however, should not be considered definitive, since the number of examined cases in the interval up to 5 months was extremely low.

\subsection{Products of intracellular erythrocyte degeneration (Fig. 5)}

Products of erythrocyte degeneration were first identified intracellularly: erythrocytes appeared $16 \mathrm{~h}$; siderin, $71 \mathrm{~h}$; and hematoidin, 13 days after the injury. Differences were observed in the length of time these products of degeneration could be identified: erythrocytes were found for the last time 150 days; and hematoidin, 365 days after the injury. Siderophages, however, were still evident for decades. The percentage of cases with few erythrophages or siderophages was comparatively high during the short or very long survival periods and comparatively low during the intervening period.

\subsection{Ceroid identification (Fig. 6)}

Ceroid was identified exclusively by autofluorescence of cytoplasmic contents in macrophages (Fig. 11). Fluorescence considered typical of ceroid (see discussion) was demonstrable in 29 of a total of 40 examined cases (63\%). The observation period ranged from $101 \mathrm{~h}$ to 216 days, related in each case to the time of the traumatic event.

Although hemoceroid was observed in isolated cases, the number of positive cases was so low that dating was impossible.

\section{Discussion}

The function of macrophages in the brain is the same as in other regions of the body, e.g. removal of foreign material. As a result, primarily macrophages are found, and even then selectively, in certain stages of aseptic inflammation. It, however, should be noted that recent studies have considered macrophages synonymous with the so-called reactive microglia $[22,23]$.

Since traumatic cortical hemorrhage serves as a stimulus for aseptic inflammation, macrophages accumulate in and around the hemorrhage site. The distribution as well as the number and functional state of the macrophages depends directly on the survival period.

In addition to the systematic studies already cited in the Introduction, the literature consists primarily of single observations. A comparison of our observations with those reported in the literature reveals the following associations: 

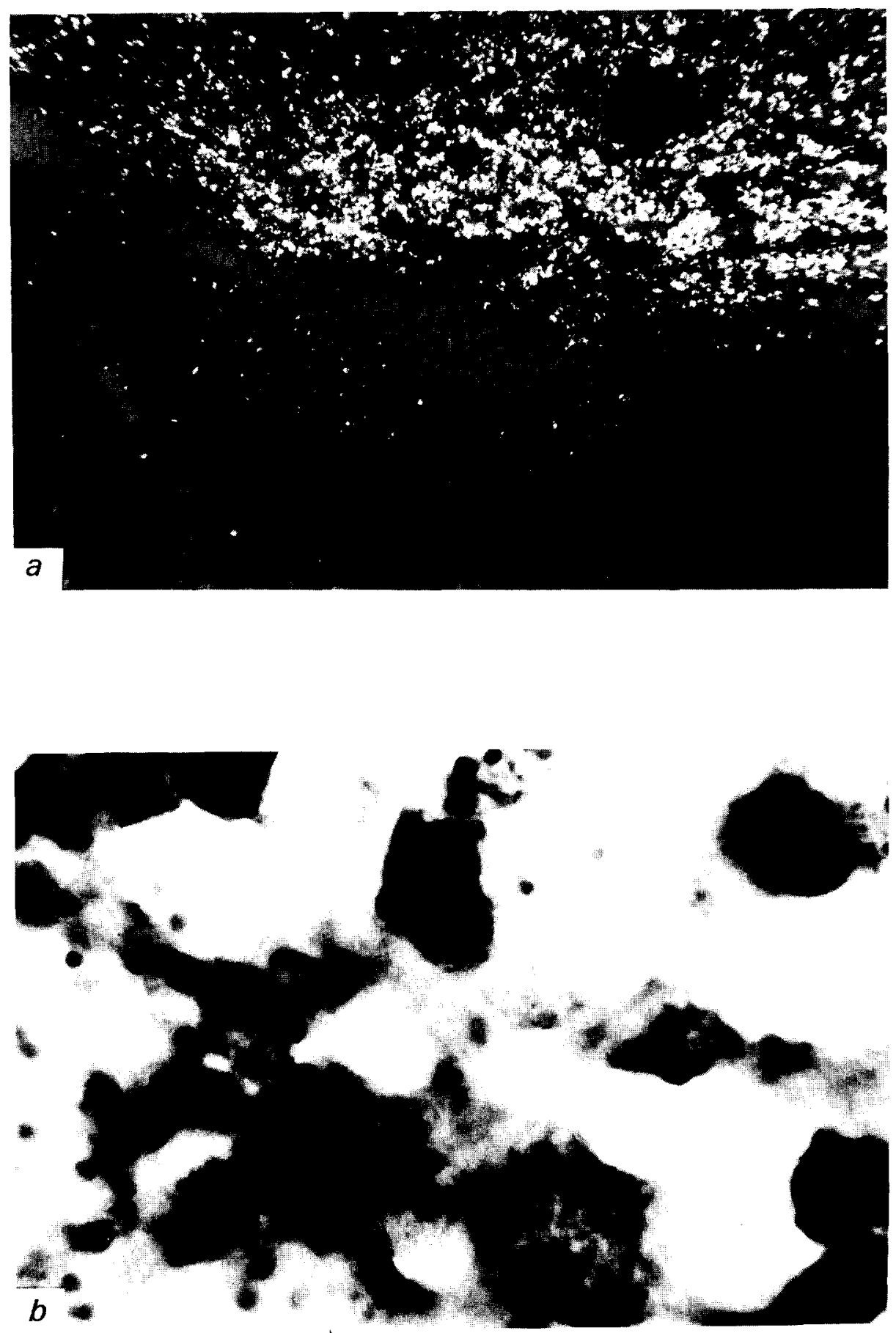


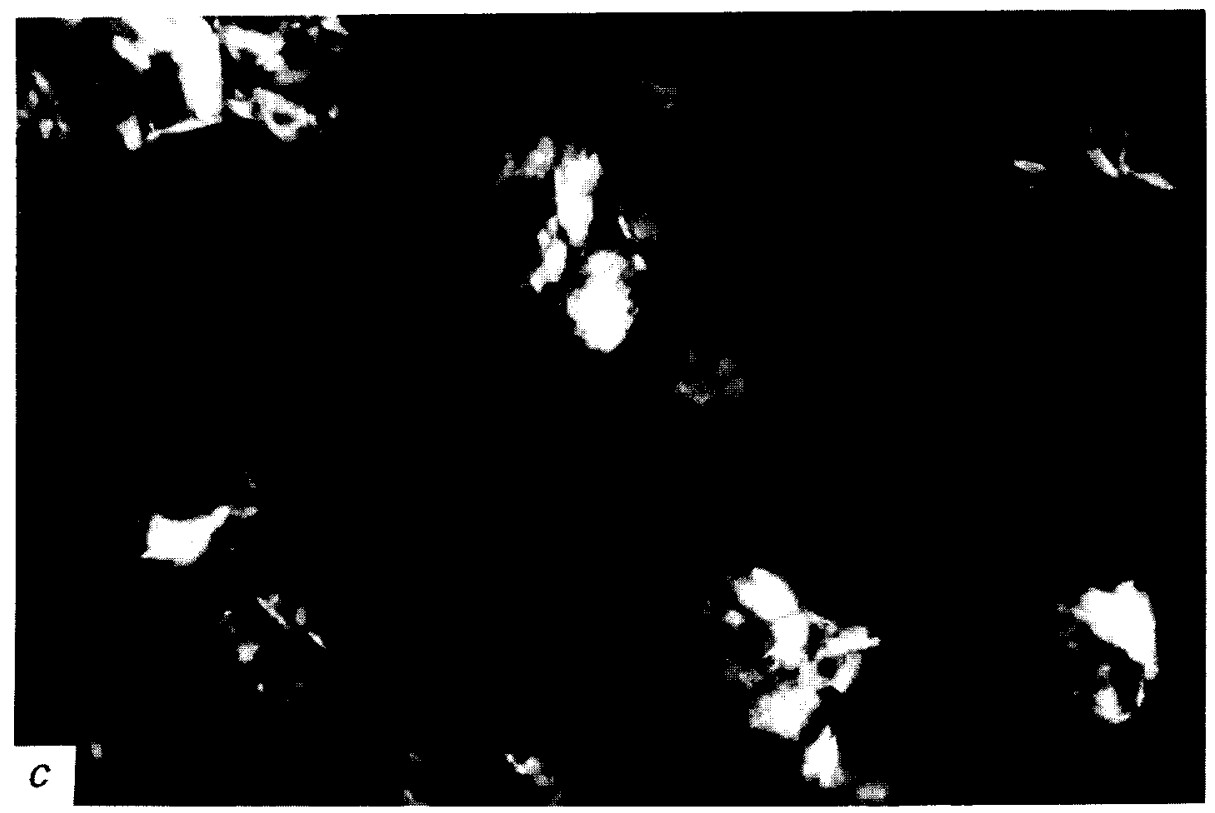

Fig. 10. Storage of anisotropic material in macrophages in overall view (a); magnification before polarization (b), and with polarization (c). (scarlet red/hemalum; $a: \times 150 ; b$, c: $\times 1200)$.

Schröder [30] who expressly mentions having searched intensively, observed macrophages in the marginal region as early as $7 \mathrm{~h}$ after ischemic brain necrosis. In single observations, other authors report the appearance of

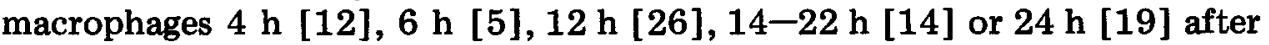
the traumatic event. The varying intervals are probably attributable, at least in part, to the different evaluation criteria used. In the present study, a certain proportion of monocytes, which in each case was higher than the relative proportion in the blood, served as positive criterium, rather than single monocytes which could be washed in with the erythrocytes. We required evidence of this monocyte "reaction" for our study.

The macrophage reaction peaked $4-5$ days [1] or 7 days $[5,17]$ after the traumatic event, a finding which corresponds well with the mitose index for macrophages in cerebral ischemia (9\% on 4 th day with gradual decline during the course of the following 2 days) presented by Schröder [30]. We also observed macrophages in $100 \%$ of all examined cases 5 days after the injury.

Only single observations on and general descriptions of the distribution of macrophages are available; no numerical analyses have been published. The reason for this paucity of information is probably the frequently encountered difficulty in differentiation, i.e. assignment of each individual case to one of the above-mentioned groups. 

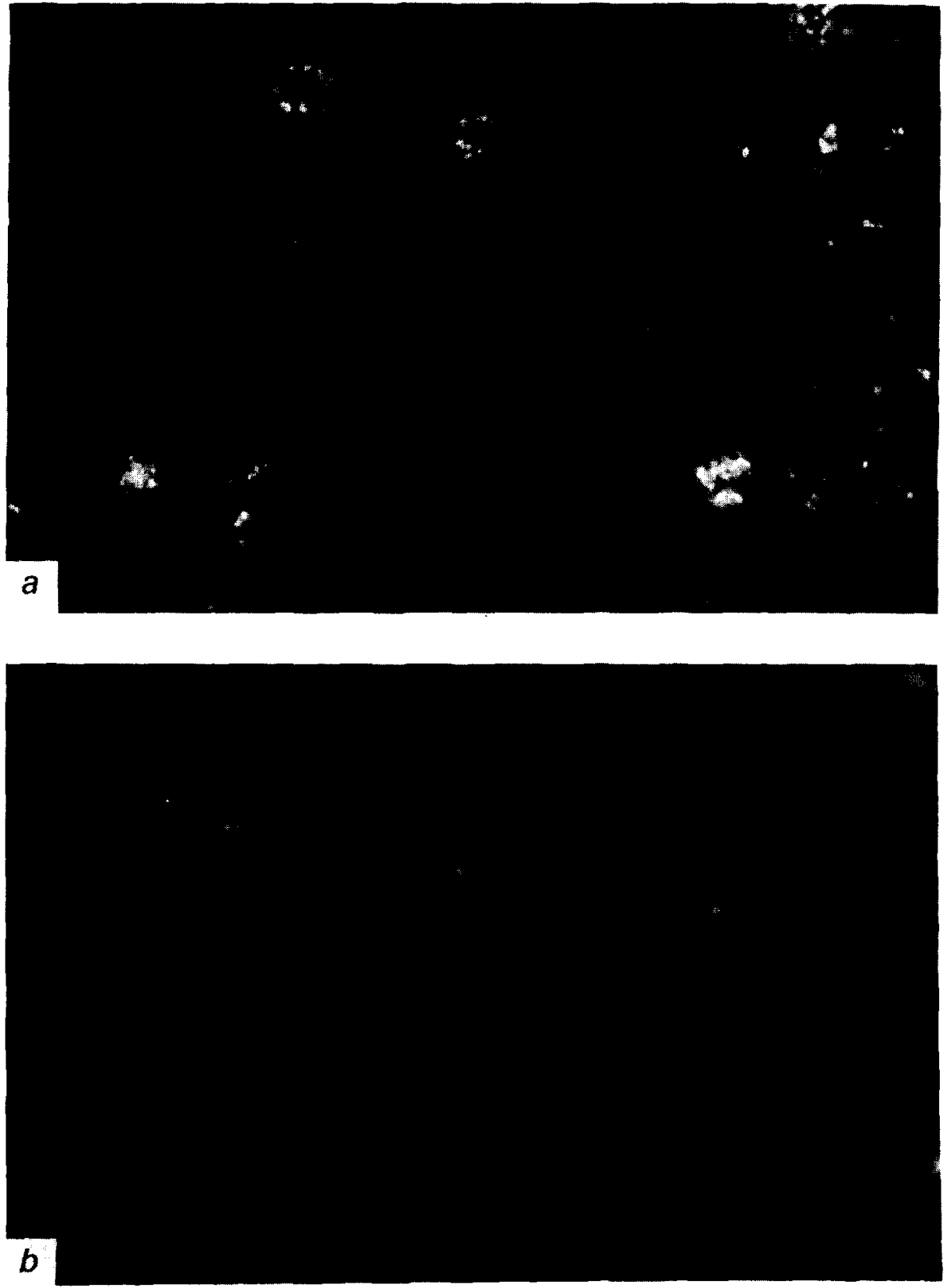

Fig. 11. Ceroid in macrophages identified by autofluorescence. Note coarse granules of varying size and quantity in different macrophages, perivascularly (a) and in necrotic field (b) $(a, b: H \& E ; \times 1200)$. 
The most important function of the macrophages is the ingestion and digestion of degenerated material, i.e. necrotic tissue and extravasated blood. In brain tissue, primarily lipid-containing tissue is ingested and broken down in the macrophages to neutral fats (i.e., triglycerides). In addition to the sudanophilic granules normally found in monocytes, we observed either a proliferation or a swelling of the granules as early as $24 \mathrm{~h}$ after the traumatic event. Five days after the injury, these granules, which at this time resemble typical fatty granule cells, were evident in all examined cases.

Most authors reported longer intervals: Meesen and Stochdorph [20] as well as Adams and Sidman [2] $48 \mathrm{~h}$; and Spielmeyer [32] $40 \mathrm{~h}$. Only Edelmann [7; cf. 5,27] described distinct fatty granule cells or their equivalents as early as $23 \mathrm{~h}$ after the traumatic event. Both Jacob [14] and Schröder [30], however, interpreted these cells as granulocytes.

Anisotropic lipids indicate esterified cholesterol; Maltese cross phenomena are sometimes observable. We found lipophages with crystalline inclusions as early as 10 days after the traumatic event; Schröder [30], however, saw them for the first time 18 days after the injury. This discrepancy is probably due to the fact that only a few of Schröder's cases fell in the 10-18-day interval.

Ceroid is a lipopigment that can arise in macrophages $[9,10]$. The only published studies on methods of identification and on time dependency are those by Schröder [29,31] who used different.methods to observe this pigment $44 \mathrm{~h}$ after an ischemic insult and was also able to demonstrate a different composition. Our study, which was limited to fluorescence methods on HE-stained sections, showed that ceroid could be definitely identified by these methods $101 \mathrm{~h}$ after the injury. Using the same methods, Schröder [29] found questionable ceroid formation up to the 8th day and definite formation after the 15th day. Since Schröder's investigatory material was not broken down into time intervals, his findings, at least for the time being, are worthy of mention but cannot be further elaborated.

Relatively few authors have described the erythrophage phenomenon. Kennady [15] first observed erythrophages $8 \mathrm{~h}$; Schröder [30] $38 \mathrm{~h}$; Adams [1] $48 \mathrm{~h}$; and Strassmann [33] 4 days after the traumatic event. Our observation that erythrophages could be identified $16 \mathrm{~h}$ after the injury fits well into the time scheme of the other authors.

We found siderophages in isolated cases with survival periods ranging from $70 \mathrm{~h}$ to $90 \mathrm{~h}$; thereafter, they were regularly evident. This observation corresponds to the findings reported by Eisenmenger [8] and Schröder [30; cf. 11,12]. Other authors, however, first observed siderophages after longer intervals (for literature, see Schröder [30]).

Hematoidin occurred both intracellularly and extracellularly. Only Strassmann [33] who observed hematoidin 10 days after the traumatic event in two cases, was able to date this crystallized bilirubin. Howarth and Couper [13] described its relatively fast absorbability; their finding corre- 
sponds to our observation that hematoidin is no longer demonstrable after a survival period of 1 year.

In summary, the reports of other investigators show both surprising similarities and considerable differences. As mentioned above, some of these variations are probably due to differences in the examined case material, since the findings were frequently based on single observations in certain survival intervals. In borderline cases, that time interval should be selected which was established in human brain tissue by identical methods during the shortest survival period. The communication of single findings, therefore, continues to be worthwhile, because such findings cannot be replaced by a statistical analysis of a large body of case material.

\section{References}

1 R.D. Adams, Implications of the biology of the neuroglia and microglia cells for clinical neuropathology. In W.F. Windle (ed.), Biology of Neuroglia, Ch.C. Thomas, Springfield, IL, 1958, pp. 245-264.

2 R.D. Adams and R.L. Sidman, Introduction to Neuropathology, McGraw-Hill, New York-Toronto-Sydney-London, 1968.

3 E.K. Adrian, Cell division in injured spinal cord. Am. J. Anat., 123 (1968) 501520.

4 A.H. Baggenstoss, J.W. Kernohan and J.F. Drapiewski, The healing process in wounds of the brain. Am. J. Clin. Pathol., 13 (1943) 333-348.

5 A.E. Carmichael, Microglia: An experimental study in rabbits after intracerebral injection of blood. J. Neurol. Psychopathol, 9 (1929) 209-216.

6 C.J. Clopper and E.S. Pearson, The use of confidence or fiducial limits illustrated in the case of the binomial. Biometrika, 26 (1934) 404-413.

7 F. Edelmann, Ein Beitrag zur Vergiftung mit gasförmiger Blausäure, insbesondere zu den dabei auftretenden Gehirnveränderungen. Dtsch. Z. Nervenheilk., 72 (1921) $259-287$.

8 W. Eisenmenger, Zur histologischen und histochemischen Altersbestimmung gedeckter Hirnrindenverletzungen. Habil-Schrift, München, 1977.

9 P. Gedigk and R. Fischer, Über die Entstehung des Ceroidpigmentes bei der hämorrhagischen Fettgewebsnekrose. Virch. Arch. Pathol. Anat., 331 (1958) 341-370.

10 P. Gedigk and W. Pioch, Über die formale Genese lipogener Pigmente. Untersuchungen mit Estern hochungesättigter Fettsäuren. Virch. Arch. Pathol. Anat., 339 (1965) $100-135$.

11 W. Hallermann and D. Illchmann-Christ, Über eigenartige Strangulationsbefunde. Z. Ges. Gerichtl. Med., 38 (1943) 97-128.

12 E.M. Hammes, Reaction of the meninges to blood. Arch. Neurol. Psychiat., 52 (1944) $505-514$.

13 F. Howarth and E.R.A. Cooper, The fate of certain foreign colloids and crystalloids after subarachnoid injection. Acta Anat. (Basel), 25 (1955) 112-140.

14 H. Jacob, Zentralnervöse Gewebsschäden und Funktionsstörungen nach Erstickungsvorgängen (Obstruktionshypoxydosen). Dtsch. Z. ges. gerichtl. Med., 51 (1961) 352368 .

15 J.C. Kennady, Investigations of the early fate and removal of subarachnoid blood. Pac. Med. Surg., 75 (1967) 163-168.

16 S. Környey, Histopathologie und klinische Symptomatologie der anoxisch-vasalen Hirnschädigungen. Akad. Kiadó, Budapest, 1955. 
17 B.W. Konigsmark and R.L. Sidman, Origin of gitter cells in the mouse brain. J. Neuropathol. exp. Neurol., 22 (1963) 327-328.

18 W. Krauland, Über die Zeitbestimmung von Schädelhirnverletzungen. Beitr. Gerichtl. Med., 30 (1973) 226-251.

19 K. Link and H. Schleussing, Die offenen Verletzungen des Gehirns und des Rückenmarks. In O. Lubarsch, F. Henke and R. Rössle (eds.) Handbuch der Speziellen Pathologischen Anatomie, Bd 13, Teil 3, pp. 22-83, Springer, Berlin-GöttingenHeidelberg, 1955.

$20 \mathrm{H}$. Meesen and O. Stochdorf, Erweichung und Blutung. In O. Lubarsch, F. Henke and R. Rössle (eds.), Handbuch der Speziellen Pathologischen Anatomie und Histologie, Bd 13, S. 1384-1419, Springer, Berlin-Göttingen-Heidelberg, 1957.

21 G. Müller, Zur Frage der Altersbestimmung histologischer Veränderungen im menschlichen Gehirn unter Berücksichtigung der örtlichen Verteilung. Zschr. Neurol. Psychiat., 124 (1930) 1-112.

$22 \mathrm{M}$. Oehmichen, Functional properties of mictoglia. In W.T. Smith and C.B. Cavanagh (eds.), Recent Advances in Neuropathology, Vol. 2, Churchill Livingstone, Edinburgh-London-New York, 1982, pp. 83-107.

$23 \mathrm{M}$. Oehmichen, Inflammatory cells in the central nervous system: An integrating concept based on recent research in pathology, immunology, and forensic medicine. In H.M. Zimmermann (ed.), Progress in Neuropathology Vol. 5, Raven Press, New York, 1983, pp. 277-335.

24 M. Oehmichen, W. Eisenmenger and G. Raff, Theoretisch-experimentelle und statistische Grundlagen zur zytomorpholegischen Altersbestimmung traumatischer Rindenblutungen. Beitr. Gerichtl. Med., 34 (1981) 57-72.

$25 \mathrm{M}$. Oehmichen and G. Raff, Timing of cortical contusion. Correlation between histomorphologic alterations and post-traumatic interval. Z. Rechtsmed., 84 (1980) 7994.

26 P. del Rio-Hortega, Poder fagocitario y movilidad de la microglia. Bol. Soc. Esp. Biol, 9 (1919) 154-166.

27 G.V. Russell, The compound granular corpuscle or gitter cell : a review, together with notes on the origin of this phagocyte. Texas Rep. Biol. Med., 20 (1962) 338-351.

28 L. Sachs, Angewandte Statistik. Statistische Methoden und ihre Anwendungen, 6. Aufl., Springer, Berlin-Heidelberg-New York, 1983.

29 R. Schröder, The lipopigments in human brain necrosis. I. Ceroid. Acta Neuropathol. (Berl.), 52 (1980) 141-145.

30 R. Schröder, Chronomorphologie der Zerebralen Durchblutungsstörungen, Springer, Berlin-Heidelberg-New York, 1983.

31 R. Schröder and B. Reinarz, The lipopigments in human brain tissue necrosis. II. Hemoceroid. Acta Neuropathol. (Berl.), 52 (1980) 147-151.

32 W. Spielmeyer, Histopathologie des Nervensystems, Springer, Berlin, 1922.

33 G. Strassmann, Formation of hemosiderin and hematoidin after traumatic and spontaneous cerebral hemorrhages. Arch. Pathol. (Chic.), 47 (1949) 205-210. 